\title{
AVALIAÇÃO RETROSPECTIVA DA URINÁLISE E MENSURAÇÃO DE CREATININA SÉRICA COMO MÉTODOS AUXILIARES NO DIAGNÓSTICO DE DOENÇA RENAL CRÔNICA EM PACIENTES CANINOS
}

\author{
PEREIRA, Sergiane Baes ${ }^{1}$; \\ GROL, Aline Azevedo Van ${ }^{2}$; \\ CONTE, Camila ${ }^{3}$; \\ GIL, Luciana Fernandes Aquini ${ }^{4}$; \\ KRAUSE, Luis Eduardo Barcellos ${ }^{4}$; \\ MEINERZ, Ana Raquel Mano ${ }^{5}$.
}

Recebido: 01/03/2019

Aceito: $21 / 08 / 2019$

\footnotetext{
${ }^{1}$ Médica Veterinária, Mestranda, Programa de Pós-Graduação em Veterinária/UFPEL; ${ }^{2}$ Médica Veterinária;

${ }^{3}$ Médica Veterinária, Pós-Graduanda, Programa de Residência Multiprofissional e em Área Profissional da Saúde/UFPEL; ${ }^{4}$ Farmacêutico-Biquímico, Técnico Administrativo em Educação/UFPEL; ${ }^{5}$ Professora, Departamento de Clínicas Veterinárias, Faculdade de Veterinária/UFPEL.
}

\section{RESUMO}

A doença renal crônica (DRC) apresenta elevados índices de morbidade em pacientes caninos, e os exames complementares possuem grande relevância para o diagnóstico, destacando-se a urinálise e a mensuração de creatinina sérica nesse sentido. Este trabalho teve como objetivo avaliar a casuística das solicitações de urinálise e mensurações de creatinina sérica em um laboratório clínico veterinário e correlacionar os achados destes testes com a suspeita clínica de disfunção renal crônica em pacientes caninos. Consistiu em um estudo retrospectivo transversal realizado no Laboratório de Patologia Clínica Veterinária da Universidade Federal de Pelotas (LPCVet-UFPEL). As variáveis de interesse foram as solicitações de urinálise e mensuração sérica de creatinina, a suspeita clínica de DRC e os resultados das análises realizadas em um período de quatro anos. Os dados foram avaliados por análise descritiva utilizando o programa Epilnfo ${ }^{T M}$. Foram observadas 2.157 solicitações para avaliação de creatinina sérica e 586 solicitações de urinálise, sendo que destas, 1,48\% (32/2.157) e 2,90\% (17/586) apresentavam suspeita clínica de DRC, respectivamente. Dentre as avaliações de creatinina sérica, 8,48\% (183/2.157) apresentaram azotemia, enquanto nas avaliações de urinálise, $21,67 \%$ (127/586) apresentaram alterações. Houve solicitação concomitante de urinálise e mensuração de creatinina sérica em $12,37 \%$ (267/2.157) dos exames, sendo que em 18,35\% (49/267) houve alterações apenas na urinálise e em 17,60\% (47/267) houve alterações em ambos os resultados. Pode-se concluir que apesar de o número de solicitações para avaliação de creatinina sérica ter sido superior ao número de solicitações de urinálise, as urinálises apresentaram maior número de resultados indicativos de DRC.

Palavras-chave: Cães. Exames Complementares. Função Renal. 


\section{INTRODUÇÃO}

A doença renal crônica (DRC) tornou-se um problema crescente na Medicina Veterinária, com elevada morbidade e mortalidade em pacientes caninos (SODRÉ et al., 2007; WAKI et al., 2010). A DRC é caracterizada por lesões irreversíveis que podem evoluir progressivamente para uremia, insuficiência renal crônica (IRC) e falência renal, sendo que a disfunção renal é proporcional à gravidade da doença, assim como seu prognóstico, tornando-se de grande importância a diferenciação entre seus estágios para adequado manejo do paciente (GALVÃO et al., 2010; WAKI et al., 2010).

Conforme classificação da International Renal Interest Society (IRIS, 2016), a DRC canina é dividida em quatro estágios (I, II, III e IV), sendo que o estágio I é considerado como estado não azotêmico. Nesse estágio não há alterações nos parâmetros bioquímicos, no entanto podem ocorrer sinais detectáveis na urinálise, como inabilidade de concentração urinária e proteinúria de origem renal. (IRIS, 2016). Nesse aspecto, os exames complementares, especialmente a urinálise, apresentam grande relevância, uma vez que visam fornecer informações além daquelas obtidas na anamnese e no exame físico, auxiliam no estabelecimento do diagnóstico, caracterizam o estágio de evolução da enfermidade, orientam as condutas terapêuticas, além do provável prognóstico (GALVÃO et al., 2010; TONELLI; LANA, 2017; WAKI et al., 2010).

$\mathrm{Na}$ rotina da clínica veterinária a urinálise e a mensuração de creatinina sérica são amplamente utilizadas para avaliação da condição renal. Nesse sentido, a urinálise apresenta como vantagens ser um teste laboratorial de triagem de fácil execução e economicamente acessível, além de ser capaz de fornecer informações não só acerca do sistema urinário, mas do organismo de forma geral. Em se tratando especificamente de pacientes com DRC, essa avaliação fornece parâmetros considerados marcadores relativamente precoces do quadro, como a densidade urinária diminuída e a presença de proteína na urina (FREITAS et al., 2014; THRALL et al., 2015).

Em contrapartida, a creatinina sérica, mesmo sendo apropriada para a avaliação da função renal, é considerado um marcador tardio para o diagnóstico de disfunção renal (FREITAS et al., 2014; THRALL et al., 2015). Esse fato é de grande relevância na rotina clínica veterinária, 
já que a detecção precoce de lesão renal e o início do tratamento são vitais para o melhor prognóstico, uma vez que $50 \%$ dos pacientes acometidos por essa condição podem vir a óbito e o tratamento apropriado reduz a incidência de falha renal irreversível (BORGES et al., 2008; FREITAS et al., 2014).

Conforme Capilheira e Santos (2006), embora se saiba que os exames complementares possuam grande utilidade, é necessário considerar alguns fatores de risco ao solicitá-los, dentre eles: o custo financeiro, o menosprezo pelo exame clínico e o atraso no diagnóstico, em circunstâncias na qual a evidência clínica seria suficiente. É comum na Medicina a realização de estudos para compreensão dos fatores relacionados à solicitação de exames complementares no Sistema Único de Saúde (SUS) e Hospitais Universitários (CAPILHEIRA; SANTOS, 2006; DENTILLO, 2012; GARCIA et al., 2014; LADEIRA, 2007;), entretanto, não foram encontrados estudos similares na Medicina Veterinária.

Sendo assim, entendendo-se a importância do estabelecimento de critérios para a solicitação de exames auxiliares, especialmente em pacientes com suspeita clínica de DRC, para que os mesmos auxiliem na melhor condução clínica do paciente, este estudo teve como objetivo avaliar a casuística das solicitações de urinálise e mensurações de creatinina sérica em um laboratório clínico veterinário e correlacionar os achados destes testes com a suspeita clínica de disfunção renal crônica em pacientes caninos.

\section{MATERIAL E MÉTODOS}

Este trabalho consistiu em um estudo retrospectivo transversal realizado no Laboratório de Patologia Clínica Veterinária da Universidade Federal de Pelotas (LPCVet-UFPEL), pertencente ao Hospital de Clínicas Veterinárias da Universidade Federal de Pelotas (HCVUFPEL). Para tanto, foram avaliadas requisições que incluíam solicitações de urinálise e mensurações de creatinina sérica, provenientes de pacientes caninos, realizadas em um período de quatro anos.

As variáveis de interesse do estudo foram as solicitações para realização de urinálise e mensuração sérica de creatinina solicitadas separadamente ou em conjunto, a justificativa para solicitação da análise (suspeita clínica de DRC) e os resultados das análises. Foi avaliado apenas o primeiro exame requisitado pelo clínico veterinário. Foram considerados como 
fatores de exclusão do estudo requisições de exames em duplicatas e provenientes de projetos de pesquisa.

As análises bioquímicas de creatinina sérica foram realizadas em equipamento automático Cobas $\mathrm{c} 111^{\circledR}$, utilizando kits comerciais. Foi considerada azotemia nos casos em que a creatinina sérica resultou em valores superiores a $1,4 \mathrm{mg} / \mathrm{dL}$, conforme parâmetro estabelecido pela IRIS (2016). As urinálises foram realizadas através de exames químico e físico da urina, e análise microscópica do sedimento urinário realizada conforme descrito por Thrall et al. (2015). Foram avaliadas a ocorrência de isostenúria (densidade urinária entre 1.008 e 1.016 na avaliação por refratometria), proteinúria (presença $\geq 1$ cruz no exame químico da amostra), hematúria (presença $\geq 1$ cruz no exame químico da amostra), e cilindrúria (presença de cilindros no exame de microscópico do sedimento urinário), achados esses considerados compatíveis com quadro de doença renal crônica (FREITAS et al., 2014; GONZÁLEZ; SILVA, 2017; WAKI et al., 2010). Os resultados que apresentaram proteinúria concomitante à presença de sangue oculto não foram considerados como resultados indicativos de proteinúria.

Os dados foram avaliados através de análise descritiva utilizando o programa Epilnfo ${ }^{\mathrm{TM}}$.

\section{RESULTADOS E DISCUSSÃO}

Durante o período analisado houve 2.157 solicitações para avaliação de creatinina sérica e 586 solicitações para realização de urinálise, demonstrando uma maior tendência na solicitação da mensuração da creatinina sérica como meio de avaliação da função renal.

Também foi observado que as avaliações de creatinina sérica foram solicitadas mediante descrição de suspeita clínica de DRC em 1,48\% (32/2.157) dos casos, enquanto a solicitação de urinálise foi realizada mediante descrição de suspeita clínica de DRC em 2,90\% (17/586) das vezes. Esse baixo número de suspeitas clínicas de DRC descritos pode ser decorrente do fato de que nos seus estágios iniciais (I e II) a enfermidade pode não demonstrar sinais clínicos ou apresentar sinais clínicos pouco específicos, tornando difícil seu reconhecimento, sendo necessários exames complementares para sua identificação (GALVÃO et al., 2010; IRIS, 2016). 
Faz-se necessário salientar quanto aos resultados do estudo que, dentre as 2.157 avaliações de creatinina sérica, 8,48\% (183/2.157) apresentaram azotemia, sendo que desses, em apenas 9,84\% (18/183) constava como suspeita clínica a DRC. Em contrapartida, das urinálises avaliadas, foi detectado que 21,67\% (127/586) dessas apresentaram proteinúria, isostenúria e/ou cilindrúria, alterações que a literatura destaca como indicadores do quadro de disfunção renal crônica (THRALL et al., 2015), sendo que em 10,23\% (13/127) dessas requisições constava suspeita clínica de DRC, conforme demonstrado na Figura 1.

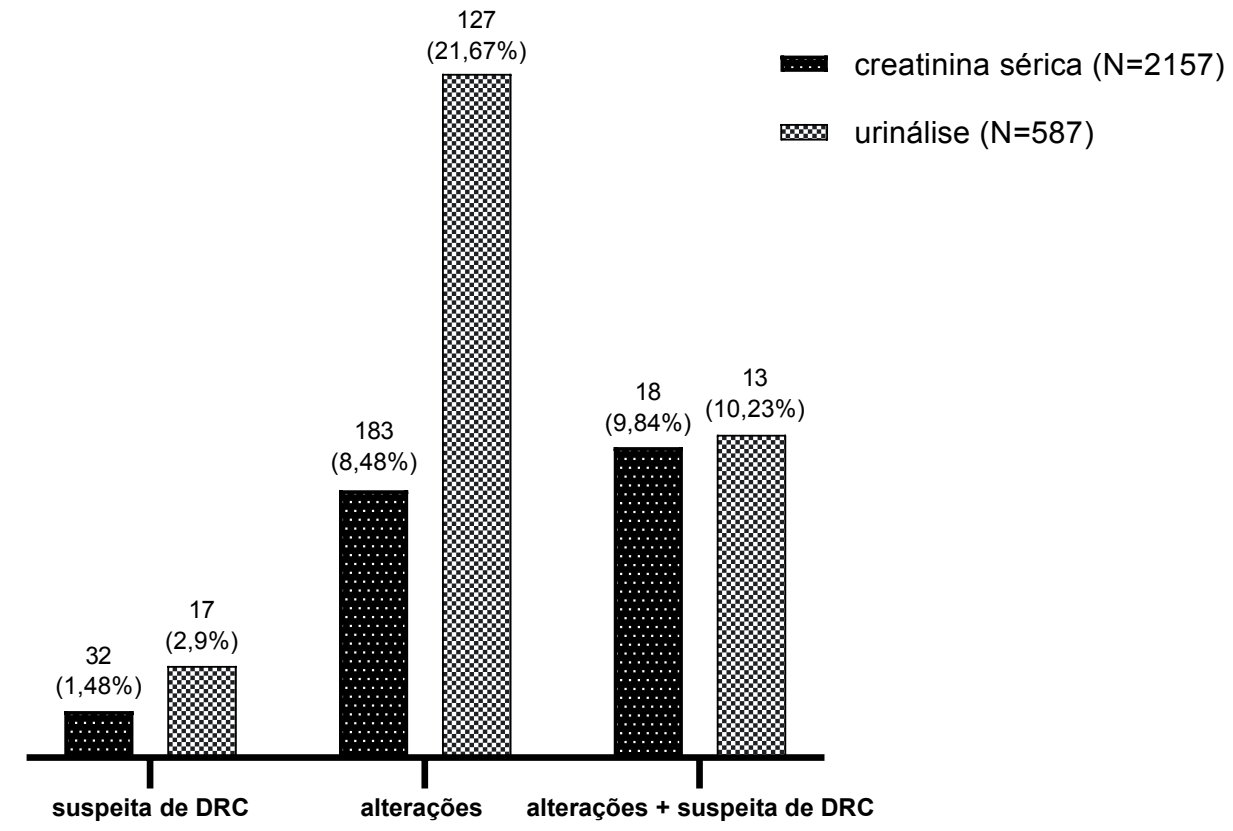

Figura 1 - Frequências de solicitações de urinálise e mensuração de creatinina sérica acompanhadas de suspeita DRC, alterações condizentes com quadro de DRC e alterações acompanhadas de suspeita de DRC, em pacientes caninos, observadas no LPCVet-UFPEL, em um período de quatro anos.

Dos casos com azotemia: 9,84\% (18/183) possuíam suspeita clínica de DRC; 9,84\% (18/183) estavam associados a suspeitas clínicas relacionadas a obstrução do fluxo urinário ou ruptura das vias excretoras urinárias, que podem cursar com azotemia de origem pós-renal; $21,31 \%$ (39/183) estavam associados a diversos quadros clínicos que podem cursar com quadro de azotemia de origem pré-renal; 22,40\% (41/183) estavam associados a suspeita 
clínica de lesões renais agudas ou nefropatias; nas demais requisições, 36,61\% (67/183), não constavam informações acerca de suspeita clínica determinada.

Esses resultados alertam para a elevada frequência de solicitações para mensuração de creatinina sérica e que tais solicitações foram pouco relacionadas com a suspeita clínica de disfunção renal crônica, criando espaço para uma análise crítica acerca da necessidade de solicitação desses exames na rotina clínica do Médico Veterinário.

Embora não tenham sido encontrados trabalhos na Medicina Veterinária acerca da casuística de solicitações de exames complementares e da necessidade de solicitação desses exames, na Medicina é observado que os requisitos para solicitação de exames, na maioria das vezes, não são seguidos, e há pouca relação dos achados clínicos dos pacientes e a solicitação de exames, sendo observado que os tipos de testes solicitados são semelhantes para pacientes em diferentes contextos (ROCHA et al., 2018). Em trabalho realizado por Tonelli e Lana (2017), ao avaliar a demanda de exames complementares na atenção primária à saúde, os autores ressaltaram que independente do fator que direcione a escolha profissional, é imprescindível que a solicitação de exames esteja acompanhada de uma justificativa plausível de acordo com critérios clínicos ou protocolos que justifiquem essa solicitação. Esse fato acerca da solicitação de exames complementares pouco relacionados com os achados clínicos pode ser também uma tendência na Medicina Veterinária, devendo o clínico veterinário também pautar sua solicitação de exames complementares em critérios clínicos ou protocolos que a justifiquem.

Dos 2.157 exames bioquímicos avaliados no presente estudo houve solicitação concomitante de urinálise em 12,37\% (267/2.157) dos exames. Em 18,35\% (49/267) dos casos houve alterações apenas na urinálise, sendo que 8,16\% (4/49) dessas análises foram acompanhadas de suspeita clínica de DRC. Em 17,60\% (47/267) dos casos foram observadas alterações em ambos os resultados, sendo 19,15\% (9/47) acompanhadas de suspeita clínica de DRC. Em 4,86\% (13/267) dos casos houve alteração apenas na creatinina sérica, sendo $15,38 \%(2 / 13)$ com suspeita clínica de DRC (Figura 2). 


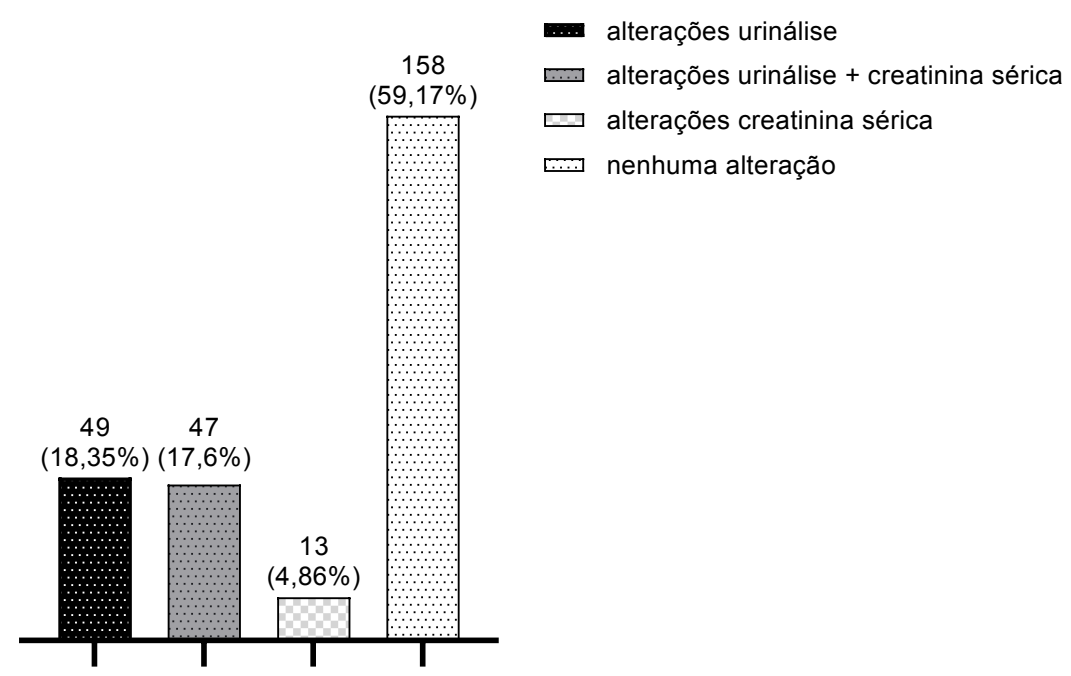

Figura 2 - Frequências de urinálises e mensurações de creatinina sérica, com alterações sugestivas de DRC em pacientes caninos, solicitadas concomitantemente ao LPCVet-UFPEL, em um período de quatro anos.

Tais resultados demonstraram que a frequência de azotemia foi mais elevada nos exames em que a urinálise já havia revelado alterações condizentes com a DRC e são semelhantes com o descrito por Lima et al. (2005) em trabalho realizado com cães com suspeita de afecção do trato urinário, no qual uma elevada percentagem dos pacientes que não apresentaram alterações no parâmetro bioquímico, apresentaram alterações físico-químicas na urinálise e na sedimentoscopia da urina.

Com relação às alterações nas urinálises, foi possível observar como mais frequentes: isostenúria (72,44\%; 92/127), seguida por cilindrúria (44,88\%; 57/127) e proteinúria (38,58\%; 49/127). Dos casos de isostenúria, 35,86\% (33/92) foram acompanhados por azotemia. Dos casos de cilindrúria, 31,57\% (18/57) foram acompanhados por azotemia. Dos casos de proteinúria, $36,73 \%$ (18/49) foram acompanhados por azotemia.

Em casos de doença renal, a isostenúria é considerada um parâmetro que reflete a inabilidade dos rins em concentrar a urina e pode se apresentar quando cerca de $66 \%$ dos néfrons forem afetados, sendo considerada uma das primeiras manifestações clínicas da DRC (GONZÁLEZ; SILVA, 2017). Enquanto que a proteinúria é a presença de proteína na urina e ocorre quando cerca de $70 \%$ dos néfrons foram atingidos, sendo considerada não só um marcador de dano glomerular, mas também um dos principais sinais de progressão de 
insuficiência renal (GONZÁLEZ; SILVA, 2017; IRIS, 2016; LAROUTE et al., 2005; THRALL et al., 2015). A ocorrência de cilindrúria observada neste estudo, caracterizou-se, em sua totalidade, na presença de cilindros granulosos, que são formados por células epiteliais e mucoproteína e podem indicar a possibilidade de necrose, pielonefrite ou infarto renal, e estão presentes em processos em progressão (FREITAS et al., 2014; THRALL et al., 2015).

A elevada frequência de isostenúria e proteinúria observadas nos resultados das urinálises vai ao encontro do fato de as urinálises terem apresentado maior frequência de alterações indicativas de DRC e do fato de a frequência da azotemia ter sido maior quando também foram observadas alterações na urinálise, uma vez que, como já mencionado, tais alterações ocorrem com menor comprometimento dos néfrons, enquanto que a alteração da creatinina sérica ocorre com comprometimento de cerca de $75 \%$, sendo, portanto, considerado um marcador de disfunção renal mais tardio (THRALL et al., 2015).

Tais resultados demonstraram elevada frequência de urinálises com alterações indicativas de disfunção renal crônica acompanhadas de azotemia, reforçando assim o previamente destacado sobre a importância de se utilizar a urinálise como um dos critérios para a solicitação da creatinina sérica quando a suspeita clínica for DRC. Nesse aspecto chama atenção, no presente estudo, o elevado número de amostras em que foi solicitada mensuração sérica de creatinina sem a solicitação paralela da urinálise, sendo que nas 1.974 análises que não apresentaram alterações séricas de creatinina não se pode descartar a possibilidade de disfunção renal crônica em seus estágios iniciais devido ao fato de a creatinina sérica ser considerado um marcador tardio (IRIS, 2016).

A literatura ressalta que a urinálise é considerada um exame de triagem, capaz de fornecer indicadores de disfunção renal com menor número de néfrons afetados, embora existam outros marcadores precoces de disfunção renal crônica como: a avaliação da gama glutamil transpeptidase urinária $(G G T)$, relação proteína:creatinina urinária e concentração de dimetilarginina simétrica (SDMA) (FREITAS et al., 2014; RELFORD et al., 2016; THRALL et al., 2015) em hospitais escola veterinários, cenário no qual foi realizado o presente estudo, que atendem uma elevada demanda de tutores em condições de vulnerabilidade social, a urinálise se constitui numa opção economicamente mais viável e capaz de fornecer 
indicadores de disfunção renal que possibilitam o diagnóstico mais precoce e consequentemente menores custos envolvidos com seu tratamento.

Cabe ressaltar que os exames laboratoriais utilizados neste estudo possuem limitações. A azotemia pode apresentar variações devido a características individuais de cada paciente, podendo ter origem extrarrenal, não sendo possível a identificação de sua origem através de avaliação bioquímica. A densidade urinária pode sofrer variações durante o dia, sendo recomendadas coletas ao longo do dia para a sua avaliação, assim como pacientes com distúrbios das adrenais apresentarem isostenúria. A avaliação da proteína pode indicar falsos positivos ou resultados positivos também devido a fatores extrarrenais (BUSH, 2004; NELSON; COUTO, 2010; THRALL et al., 2015).

Entretanto, tendo em vista os resultados observados, pode-se demonstrar a elevada relevância da urinálise como exame de rotina indicativo para o diagnóstico precoce de disfunção renal crônica. As alterações observadas nessas análises, em conjunto com os sinais clínicos e demais biomarcadores e exames complementares, podem auxiliar o clínico veterinário em sua investigação diagnóstica assim como no monitoramento clínico do quadro, diminuindo a ocorrência de falha renal irreversível (ABENSUR, 2011; BORGES et al., 2008; THRALL et al., 2015).

\section{CONCLUSÃO}

Em vista do exposto, apesar de o número de solicitações de mensuração de creatinina sérica ter sido maior, as urinálises apresentaram maior número de resultados indicativos de disfunção renal crônica, especialmente quando as solicitações vinham acompanhadas com histórico dessa suspeita. 


\title{
RETROSPECTIVE EVALUATION OF URINALYSIS AND MEASUREMENT OF SERUM CREATININE AS AUXILIARY METHODS FOR DIAGNOSIS OF CHRONIC RENAL DISEASE IN CANINE PATIENTS
}

\begin{abstract}
$\longrightarrow$ hronic kidney disease (CKD) presents high morbidity rates in canine patients, and the complementary exams are of great relevance for diagnosis, especially urinalysis and measurement of serum creatinine in this sense. The purpose of this study was to evaluate the casuistry of urinalysis and serum creatinine measurements in a veterinary clinical laboratory and to correlate the findings of these tests with the clinical suspicion of chronic renal dysfunction in canine patients. The study consisted of a retrospective crosssectional study conducted at the Laboratory of Veterinary Clinical Pathology, Federal University of Pelotas (LPCVet-UFPEL). The variables of interest were the urinalysis and serum measurements of creatinine, the clinical suspicion of CKD and the results of the analyses performed in a period of four years. Data were evaluated through descriptive analysis using the Epilnfo ${ }^{\text {TM }}$ program. A total of 2,157 serum creatinine and 586 urinalysis requests were observed. Of these, $1.48 \%(32 / 2,157)$ and $2.90 \%(17 / 586)$ presented clinical suspicion of CKD, respectively. Among the serum creatinine assessments, $8.48 \%(183 / 2,157)$ presented azotemia, whereas in urinalysis, $21.67 \%$ (127/586) presented alterations. There was a concurrent urinalysis and serum creatinine measurement in $12.37 \%(267 / 2,157)$ of the exams, 18.35\% (49/267) had changes only in urinalysis and in $17.60 \%(47 / 267)$ there were changes in both results. It was possible to conclude that although the number of requests for serum creatinine evaluation was higher than the number of urinalysis requests, the latter presented a higher number of results indicatives of CKD.
\end{abstract}

Keywords: Complementary Exams. Dogs. Renal Function.

\section{EVALUACIÓN RETROSPECTIVA DEL UROANÁLISIS Y MEDICIÓN DE CREATININA SÉRICA COMO MÉTODOS AUXILIARES EN EL DIAGNÓSTICO DE ENFERMEDAD RENAL CRÓNICA EN PACIENTES CANINOS}

\section{RESUMEN}

a enfermedad renal crónica (ERC) presenta altos índices de morbilidad en pacientes caninos, teniendo los exámenes complementarios, gran relevancia para el diagnóstico, destacándose el uroanálisis y la medición de creatinina sérica. El estudio tiene como objetivo evaluar la casuística de las solicitudes de uroanálisis y mediciones de creatinina sérica en un laboratorio clínico veterinario y correlacionar los hallazgos en esas pruebas con 
la sospechosa clínica de disfunción renal crónica en pacientes caninos. Consistió en un estudio retrospectivo transversal realizado en el Laboratorio de Patología Clínica Veterinaria de la Universidad Federal de Pelotas (LPCVet-UFPEL). Las variables de interés fueron la solicitud de uroanálisis y las mediciones de creatinina sérica, la sospechosa clínica de ERC y los resultados de los análisis realizados en un período de cuatro años. Los datos fueron evaluados a través de análisis descriptivo utilizando el programa Epilnfo ${ }^{\mathrm{TM}}$. Se evaluaron 2.157 solicitudes para evaluación de creatinina sérica y 586 solicitudes de uroanálisis, siendo que 1,48\% (32/2.157) y el 2,90\% (17/586) presentaban sospechas clínicas de ERC, respectivamente. Entre las evaluaciones de creatinina sérica, el 8,48\% (183/2.157) presentaron azotemia, mientras que en los uroanálisis, el 21,67\% (127/586) presentaron alteraciones. Hubo una solicitud concomitante de uroanálisis y medición de creatinina sérica en el 12,37\% (267/2.157) de los exámenes. En el 18,35\% (49/267) hubo alteraciones sólo en la uroanálisis y en el $17,60 \%$ (47/267), hubo alteraciones en ambos resultados. Se puede concluir que el número de solicitudes para evaluación de creatinina sérica fue superior al número de solicitudes de uroanálisis, sin embargo las de uroanálisis presentaron mayor número de resultados indicativos de ERC.

Palabras clave: Exámenes Complementarios. Función Renal. Perros.

\section{REFERÊNCIAS}

ABENSUR, H. Biomarcadores na Nefrologia. 2011. Disponível em http://arquivos.sbn.org.br/pdf/biomarcadores.pdf . Acesso em 12 nov. 2018.

BORGES, K. E.; POLIZER, K. A.; SILVÉRIO, M. R.; GIMENES, T. F.; BERMEJO, V. J.; SACCO, S. R. Exames de função renal utilizados na medicina veterinária. Revista Científica Eletrônica de Medicina Veterinária, Garça, v. 6, n. 11, p. 1-6, 2008.

BUSH, B. M. Interpretação de Resultados Laboratoriais para Clínicos de Pequenos Animais. São Paulo: Roca, 2004. 384p.

CAPILHEIRA, M. F.; SANTOS, I. S. Epidemiologia da solicitação de exame complementar em consultas médicas. Revista de Saúde Pública, v. 40, n. 2, p. 289-297, 2006.

DENTILLO, D. B. Excesso de exames para deteç̧ão de doenças pode gerar diagnósticos prematuros e ações desnecessárias. Ciência e Cultura, v. 64, n. 3, p. 10-13, 2012.

FREITAS, G. C.; VEADO, J. C. C.; CARREGARO, A. B. Teste de avaliação da injúria renal precoce em cães e gatos. Semina: Ciências Agrárias, Londrina, v. 35, n. 1, p. 411-426, 2014. 
GALVÃO, A. L. B.; BORGES, J. C.; VIEIRA, M. C.; FERREIRA, G.; LÉGA, E.; PINTO, M. Alterações clínicas e laboratoriais de cães e gatos com doença renal crônica: revisão de literatura. Nucleus Animalium, Ituverava, v. 2, n. 1, p. 23-40, 2010.

GARCIA, A. P.; PASTORIO, K. A.; NUNES, R. L.; LOCKS, G. F.; ALMEIDA, M. C. S. Indicación de exámenes preoperatorios según criterios clínicos: necesidad de supervisión. Brazilian Journal of Anesthesiology, v. 64, n. 1, p. 54-61, 2014.

GONZÁLEZ, F. H. D.; SILVA, S. C. Introdução à Bioquímica Clínica Veterinária. 3. ed. Porto Alegre: Editora da UFRGS, 2017. 538p.

IRIS - INTERNATIONAL RENAL INTEREST SOCIETY. Stating of CKD, 2016. Disponível em: $<$ http://www.iris-kidney.com/pdf/3_staging-of-ckd.pdf> .

LADEIRA, M. C. B. A necessidade de exames complementares pré-operatórios. Revista do Hospital Universitário Pedro Ernesto, v. 6, n. 2, p. 20-27, 2007.

LAROUTE, V.; CHETBOUL, V.; ROCHE, L.; MAUREY, C.; COSTES, G.; OUCHELON, J. L.; FARGE, F. L.; BOUSSOUF, M.; LEFEBVRE, H. P. Quantitative evaluation of renal function in healthy Beagle puppies and mature dogs. Research in Veterinary Science, v. 79, n. 1, p. 161-167, 2005.

LIMA, A. D. M.; AMÓRA, S. S. A.; FILGUEIRA, K. D.; FEIJÓ, F. M. C.; ALVES, F. R. P.; FRANKLIN, A. S.; ALVES, N. D. Análise dos parâmetros bioquímicos e urinários de cães com suspeita de afecção do sistema urinário. Ciência Animal, v. 15, n. 1, p .43-47, 2005.

NELSON, R. W.; COUTO, C. G. Distúrbios da Glândula Adrenal. In: NELSON, R. W.; COUTO, C. G. Medicina Interna de Pequenos Animais. 4. ed. São Paulo: Elsevier, 2010. P. 812-832.

RELFORD, R.; ROBERTON, J.; CLEMENTS, C. Symmetric dimethylarginine: Improving the diagnosis and staging of chronic kidney disease in small animals. Veterinary Clinics of North America: Small Animal Practice, v. 46, n. 6, p. 941-960, 2016.

ROCHA, E. C. B.; LIMA, L. J. L; ALMEIDA, M. V. G.; LOPES, M. R. Necessidade de gerenciamento dos gastos com exames laboratoriais no Brasil. Revista de Educação do Vale do São Francisco, v. 8, n. 15, p. 112-128, 2018.

SODRÉ, F. L.; BARRETO COSTA, J. C.; LIMA, J. C. C. Avaliação da função e da lesão renal: um desafio laboratorial. Jornal Brasileiro de Patologia Clínica / Medicina Laboratorial, Rio de Janeiro, v. 43, n. 5, p. 329-337, 2007.

THRALL, M. A.; WEISER, G.; ALLISON, R. W.; CAMPBELL, T. W. Hematologia e Bioquímica Clínica Veterinária. 2. ed. São Paulo: Rocca, 2015. 582p. 
TONELLI, I. S.; LANA, F. C. F. Demanda de exames complementares de média complexidade na atenção primária à saúde. Revista Baiana de Enfermagem, v. 31, n. 3, p. 1-10, 2017.

WAKI, M. F.; MARTORELLI, C. R.; MOSKO, P. E.; KOGIKA, M. K. Classificação em estágios da doença renal crônica em cães e gatos - abordagem clínica, laboratorial e terapêutica. Ciência Rural, Santa Maria, v. 10, n. 10, p. 2226-2234, 2010.

Autor para correspondência: Sergiane Baes Pereira. Universidade Federal de Pelotas, Faculdade de Veterinária, Campus Universitário, caixa postal 354, CEP 96010 900, Capão do Leão (RS), Brasil. sergiiane@hotmail.com 